\title{
Gambaran skor MMSE dan MoCA-INA pada pasien cedera kepala ringan dan sedang yang dirawat di RSUP Prof. Dr. R. D. Kandou Manado
}

\author{
${ }^{1}$ Nurindah Athika \\ ${ }^{2}$ Junita Maja P. S. \\ ${ }^{2}$ Arthur H. P. Mawuntu
}
${ }^{1}$ Kandidat Skripsi Fakultas Kedokteran Universitas Sam Ratulangi Manado
${ }^{2}$ Bagian Ilmu Neurologi Fakultas Kedokteran Universitas Sam Ratulangi
Email: athikanurindah@yahoo.com

\begin{abstract}
Traumatic Brain Injury (TBI) is the most common case in hospital. TBI can caused cognitive impairment. This study aimed to obtain the description of cognitive function in patients with mild and moderate TBI that were admitted to Prof. Dr. R. D. Kandou Hospital Manado. This was a prospective descriptive study by conducting direct examination to the patients diagnosed with mild or moderate TBI by using MMSE and Ina MoCA instruments. Thee results showed that there of 50 subjects there were $74 \%$ with mild TBI and $26 \%$ with moderate TBI. MMSE showed 96\% normal while Ina MoCA showed 76\% normal. Cognitive function impairment was more visible on Ina MoCA examination. Conclusion: Ina MoCA was better than MMSE examination in description of cognitive function impairment. Keywords: head injury, cognitive function
\end{abstract}

\begin{abstract}
Abstrak: Cedera kepala merupakan suatu kegawatan yang paling sering dijumpai di Rumah Sakit. Cedera kepala dapat menyebabkan gangguan fungsi kognitif. Penelitian ini bertujuan untuk mengetahui gambaran skor MMSE dan MoCA-Ina pada pasien cedera kepala ringan dan sedang yang dirawat di RSUP Prof. Dr. R. D. Kandou Manado. Jenis penelitian ini ialah deskriptif prospektif dengan melakukan pemeriksaan langsung pada pasien yang didiagnosis cedera kepala ringan atau sedang menggunakan instrumen MMSE dan MoCA-Ina. Hasil penelitian mendapatkan subjek sebanyak 50 orang dengan persentase cedera kepala ringan sebanyak 74\% dan cedera kepala sedang 26\%. Pada MMSE didapatkan 96\% normal sedangkan pada MoCA-Ina didapatkan 76\% normal. Penurunan fungsi kognitif lebih terlihat pada pemeriksaan MoCA-Ina. Simpulan: MoCA-Ina lebih dapat menggambarkan gangguan fungsi kognitif daripada pemeriksaan MMSE.
\end{abstract}

Kata kunci: cedera kepala, fungsi kognitif

Cedera kepala merupakan suatu kegawatan yang paling sering dijumpai di unit gawat darurat suatu rumah sakit. Cedera kepala dapat berakibat gangguan pada fungsi normal otak karena trauma tumpul maupun tajam, tetapi tidak semua orang yang mengalami cedera kepala akan mengalami behavioral effects atau disabilitas lain yang berhubungan dengan cedera kepala. ${ }^{1,2}$

Setiap tahun di Amerika Serikat, paling sedikit 1,7 juta orang mencari pertolongan medis karena cedera kepala. Selain itu, cedera kepala merupakan salah satu dari tiga faktor penyebab kematian akibat cedera di Amerika Serikat. ${ }^{3}$ Di negara berkembang seperti Indonesia, perkembangan ekonomi dan industri memberikan dampak frekuensi cedera kepala cenderung semakin meningkat. Data epidemiologi di Indonesia belum ada, tetapi data dari salah satu rumah sakit di Jakarta, RS Cipto Mangunkusumo, untuk penderita 
rawat inap, terdapat $60 \%-70 \%$ dengan cedera kepala ringan (CKR), 15\%-20\% cedera kepala sedang (CKS), dan sekitar 10\% dengan cedera kepala berat (CKB). Data dari Perhimpunan Dokter Spesialis Saraf Indonesia (PERDOSSI) tahun 2007 melaporkan bahwa angka kematian tertinggi sekitar 35\%-50\% akibat CKB, 5\%-10\% CKS, sedangkan untuk CKR tidak ada yang meninggal., ${ }^{4,5}$

Salah satu komplikasi dan akibat dari cedera kepala ialah beberapa pasien mungkin mengalami gangguan fungsi kognitif. $^{6}$ Defisit kognitif yang sering muncul setelah cedera kepala ialah gangguan memori, konsentrasi dan pemusatan perhatian, kecepatan memproses informasi dan fungsi eksekutif. Kognitif yaitu suatu proses dimana semua masukan sensoris (taktil, visual, auditorik) akan diubah, diolah disimpan dan selanjutnya digunakan untuk hubungan interneuron secara sempurna sehingga individu mampu melakukan penalaran terhadap masukan sensoris tersebut. Fungsi kognitif mencakup 5 domain, yaitu: attention (pemusatan perhatian), language (bahasa), memory (daya ingat), visuospatial (pengenalan ruang), dan executive function (fungsi eksekutif; perencanaan, pengorganisasian dan pelaksanaan). ${ }^{7}$

Terdapat beberapa cara untuk memeriksa gangguan fungsi kognitif, diantaranya Mini Mental State Examination (MMSE) dan Montreal Cognitive Assessment versi Indonesi (MoCA-Ina). ${ }^{8,9}$ MMSE dan MoCA-Ina bersama-sama disajikan dalam satu halaman dan diberikan dalam waktu 10-15 menit. MMSE dan MoCA-Ina juga memiliki skor maksimum yang sama yaitu 30 poin. ${ }^{10}$

Penelitian ini bertujuan untuk melihat gambaran skor MMSE dan MoCA-Ina pada pasien cedera kepala di RSUP Prof. Dr. R. D. Kandou Manado.

\section{METODE PENELITIAN}

Jenis penelitian ini ialah deskriptif dengan desain potong lintang. Dilakukan pemeriksaan pada pasien CKR dan CKS yang dirawat di RSUP Prof. Dr. R. D.
Kandou Manado. Penelitian ini dilakukan selama dua bulan, yaitu pada akhir bulan November 2015 sampai pertengahan bulan Januari 2016. Populasi penelitian ialah pasien yang dirawat di RSUP Prof. Dr. R. D. Kandou Manado. Sampel penelitian ialah pasien CKR dan CKSyang dirawat di RSUP Prof. Dr. R. D. Kandou Manado.

\section{HASIL PENELITIAN}

Berdasarkan hasil penelitian yang di lakukan di RSUP. Prof. Dr. R. D. Kandou selama 2 bulan, didapatkan subyek penelitian berjumlah 50 pasien.

Tabel 1 memperlihatkan bahwa subjek terbanyak ialah laki-laki (72\%). Dalam kelompok usia, persentase terbanyak berada dalam kelompok usia 12-20 tahun (22\%) dan dalam kelompok pendidikan terbanyak ialah SMA (74\%). Untuk beratnya cedera kepala terlihat bahwa kelompok subjek tertinggi ialah CKR (74\%).

Tabel 1. Distribusi karakteristik umum subjek penelitian

\begin{tabular}{lcc}
\hline $\begin{array}{c}\text { Karakteristik } \\
\text { Umum }\end{array}$ & (n) & (\%) \\
$\begin{array}{c}\text { Jenis Kelamin } \\
\text { o }\end{array}$ & 36 & 72 \\
$\quad+$ & 14 & 28 \\
$\quad$ Total & 50 & 100 \\
\hline Usia (tahun) & & \\
$\quad 12-20$ & 22 & 44 \\
$\quad 21-30$ & 12 & 24 \\
$\quad 31-40$ & 5 & 10 \\
$\quad>40$ & 11 & 22 \\
Total & 50 & 100 \\
\hline Pendidikan & & \\
Tidak sekolah & - & - \\
SD & 3 & 6 \\
SMP & 8 & 16 \\
SMA & 37 & 74 \\
Perguruan & 2 & 4 \\
Tinggi & & \\
Total & 50 & 100 \\
\hline Berat Cedera & & \\
CKR & 37 & 74 \\
CKS & 13 & 26 \\
Total & 50 & 100 \\
\hline
\end{tabular}


Pada Tabel 2 terlihat bahwa skor MMSE normal subjek CKR ialah 74\% dari total subjek cedera kepala. Untuk skor MMSE normal subjek CKS ialah 24\% dari total subjek cedera kepala. Untuk skor MMSE yang probable gangguan kognitif pada subjek CKR tidak ada sedangkan pada subjek CKS 4\%.

Skor fungsi kognitif menggunakan MoCA-Ina terlihat bahwa subjek CKR dengan skor MOCA-INA normal sebanyak 64\% dan subjek CKS dengan skor MOCAINA normal sebanyak $12 \%$. Untuk gangguan fungsi kognitif ringan subjek terbanyak yaitu CKS (10\%) dan untuk gangguan kognitif sedang terbanyak pada subjek CKS (4\% dari total sampel cedera kepala). Untuk gangguan fungsi kognitif berat tidak ditemukan pada kedua variabel.

Dari Tabel 4 terlihat bahwa pada MMSE bagian yang paling banyak mengalami kemunduran ialah atensi dan kalkulasi.

Dari Tabel 5 terlihat bahwa Hasil MoCA-Ina yang mengalami gangguan fungsi kognitif menunjukkan adanya kemunduran pada 3-4 bagian MoCA-Ina. Bagian yang paling banyak mengalami kemunduran ialah bagian atensi, visuospasial/eksekutif, dan delayed recall.

Tabel 2. Distribusi skor MMSE berdasarkan variabel yang diteliti

\begin{tabular}{|c|c|c|c|c|c|c|}
\hline \multicolumn{7}{|c|}{ MMSE } \\
\hline \multirow{2}{*}{ Variabel } & \multicolumn{2}{|c|}{ Normal } & \multicolumn{2}{|c|}{ Probable } & \multicolumn{2}{|c|}{ Definite } \\
\hline & $\mathrm{n}$ & $\%$ & $\mathrm{n}$ & $\%$ & $\mathrm{n}$ & $\%$ \\
\hline \multicolumn{7}{|l|}{ Jenis Kelamin } \\
\hline$\widehat{0}$ & 34 & 71 & 2 & 100 & - & - \\
\hline 우 & 14 & 29 & - & - & - & - \\
\hline Total & 48 & 100 & 2 & 100 & - & - \\
\hline \multicolumn{7}{|l|}{ Usia } \\
\hline $12-20$ thn & 22 & 46 & - & - & - & - \\
\hline $21-30$ thn & 11 & 25 & - & - & - & - \\
\hline $31-40$ thn & 4 & 8 & 1 & 50 & - & - \\
\hline$>40$ thn & 10 & 21 & 1 & 50 & - & - \\
\hline Total & 48 & 100 & 2 & 100 & - & - \\
\hline \multicolumn{7}{|l|}{ Pendidikan } \\
\hline SD & 2 & 4 & 1 & 50 & - & - \\
\hline SMP & 8 & 17 & - & - & - & - \\
\hline SMA & 26 & 75 & 1 & 50 & - & - \\
\hline Perguruan Tinggi & 2 & 4 & - & - & - & - \\
\hline Total & 48 & 100 & 2 & 100 & - & - \\
\hline Berat Cedera & & & & & & \\
\hline CKR & 37 & 73 & - & - & - & - \\
\hline CKS & 11 & 23 & 2 & 100 & - & - \\
\hline Total & 48 & 100 & 2 & 100 & - & - \\
\hline MoCA-Ina & & & & & & \\
\hline Normal (26-30) & 38 & 79 & - & - & - & - \\
\hline Ringan (20-26) & 9 & 19 & - & - & - & - \\
\hline Sedang (10-19) & 1 & 2 & 2 & 100 & - & - \\
\hline Berat (0-9) & - & - & - & - & - & - \\
\hline Total & 48 & 100 & 2 & 100 & - & - \\
\hline
\end{tabular}


Tabel 3. Distribusi skor MoCA-Ina berdasarkan variabel yang diteliti

\begin{tabular}{|c|c|c|c|c|c|c|c|c|}
\hline \multicolumn{9}{|c|}{ MOCA-INA } \\
\hline \multirow[t]{2}{*}{ Variabel } & \multicolumn{2}{|c|}{$\begin{array}{l}\text { Normal } \\
(26-30)\end{array}$} & \multicolumn{2}{|c|}{$\begin{array}{c}\text { Gangguan } \\
\text { Ringan } \\
(20-25)\end{array}$} & \multicolumn{2}{|c|}{$\begin{array}{c}\text { Gangguan } \\
\text { Sedang } \\
(10-19)\end{array}$} & \multicolumn{2}{|c|}{$\begin{array}{c}\text { Gangguan Berat } \\
(0-9)\end{array}$} \\
\hline & $\mathrm{n}$ & $\%$ & $\mathrm{n}$ & $\%$ & $\mathrm{n}$ & $\%$ & $\%$ & $\mathrm{n}$ \\
\hline \multicolumn{9}{|l|}{ Jenis Kelamin } \\
\hline$\hat{0}$ & 14 & 37 & 9 & 100 & 3 & 100 & - & - \\
\hline q & 24 & 63 & - & - & - & - & - & - \\
\hline Total & 38 & 100 & 9 & 100 & 3 & 100 & - & - \\
\hline \multicolumn{9}{|l|}{ Usia } \\
\hline $12-20$ thn & 18 & 47 & 4 & 45 & - & - & - & - \\
\hline $21-30$ thn & 9 & 24 & 3 & 33 & - & - & - & - \\
\hline $31-40$ thn & 3 & 8 & 1 & 11 & 1 & 33 & - & - \\
\hline$>40$ thn & 8 & 21 & 1 & 11 & 2 & 67 & - & - \\
\hline Total & 38 & 100 & 9 & 100 & 3 & 100 & - & - \\
\hline \multicolumn{9}{|l|}{ Pendidikan } \\
\hline SD & 2 & 5 & - & - & 1 & 33,3 & - & - \\
\hline SMP & 6 & 16 & 1 & 11 & 1 & 33,3 & - & - \\
\hline SMA & 29 & 76 & 7 & 78 & 1 & 33,3 & - & - \\
\hline Perguruan tinggi & 1 & 3 & 1 & 11 & - & - & - & - \\
\hline Total & 38 & 100 & 9 & 100 & 3 & 100 & - & - \\
\hline \multicolumn{9}{|l|}{ Berat Cedera } \\
\hline CKR & 32 & 84 & 4 & 44 & 1 & 33 & - & - \\
\hline CKS & 6 & 16 & 5 & 56 & 2 & 67 & - & - \\
\hline Total & 38 & 100 & 9 & 100 & 3 & 100 & - & - \\
\hline \multicolumn{9}{|l|}{ MMSE } \\
\hline $\begin{array}{l}\text { Normal } \\
(24-30)\end{array}$ & 38 & 100 & 9 & 100 & 1 & 33 & - & - \\
\hline $\begin{array}{l}\text { Probable } \\
(17-23)\end{array}$ & - & - & - & - & 2 & 67 & - & - \\
\hline $\begin{array}{l}\text { Definite } \\
(0-16)\end{array}$ & - & - & - & - & - & - & - & - \\
\hline Total & 38 & 100 & 9 & 100 & 3 & 100 & - & - \\
\hline
\end{tabular}

Tabel 4. Distribusi penurunan komponen MMSE menurut variabel yang diteliti

\begin{tabular}{|c|c|c|c|c|c|c|c|c|c|c|}
\hline \multicolumn{11}{|c|}{ MMSE } \\
\hline \multirow[t]{2}{*}{ Variabel } & \multicolumn{2}{|c|}{ Orientasi } & \multicolumn{2}{|c|}{ Registrasi } & \multicolumn{2}{|c|}{$\begin{array}{l}\text { Atensi \& } \\
\text { Kalkulasi }\end{array}$} & \multicolumn{2}{|c|}{$\begin{array}{l}\text { Mengingat } \\
\text { Kembali } \\
\text { (Recall) }\end{array}$} & \multicolumn{2}{|c|}{ Bahasa } \\
\hline & $\mathrm{n}$ & $\%$ & $\mathrm{n}$ & $\%$ & $\mathrm{n}$ & $\%$ & $n$ & $\%$ & $\mathrm{n}$ & $\%$ \\
\hline \multicolumn{11}{|l|}{ Jenis Kelamin } \\
\hline$\hat{\sigma}$ & 2 & - & - & - & 12 & 80 & 9 & 90 & 3 & 50 \\
\hline 우 & - & - & - & - & 3 & 20 & 1 & 10 & 3 & 50 \\
\hline Total & 2 & 100 & - & - & 15 & 100 & 10 & 100 & 6 & 100 \\
\hline \multicolumn{11}{|l|}{ Usia } \\
\hline $12-20$ thn & - & - & - & - & 9 & 60 & 5 & 50 & - & - \\
\hline $21-30$ thn & 1 & 50 & - & - & 1 & 7 & 1 & 10 & 1 & 17 \\
\hline $31-40$ thn & - & - & - & - & 2 & 13 & 1 & 10 & 1 & 17 \\
\hline$>40$ thn & 1 & 50 & - & - & 3 & 20 & 3 & 30 & 4 & 66 \\
\hline Total & 2 & 100 & - & - & 15 & 100 & 10 & 100 & 6 & 100 \\
\hline
\end{tabular}




\begin{tabular}{|c|c|c|c|c|c|c|c|c|c|c|}
\hline \multicolumn{11}{|l|}{ Pendidikan } \\
\hline SD & - & - & - & - & 1 & 7 & - & - & 2 & 33 \\
\hline SMP & 1 & 50 & - & - & 2 & 13 & 2 & 20 & 1 & 17 \\
\hline SMA & 1 & 50 & - & - & 12 & 80 & 8 & 80 & 3 & 50 \\
\hline Perguruan Tinggi & - & - & - & - & - & - & - & - & - & - \\
\hline Total & 2 & 100 & - & - & 15 & 100 & 10 & 100 & 6 & 100 \\
\hline \multicolumn{11}{|l|}{ Berat Cedera } \\
\hline CKR & 2 & 100 & - & - & 9 & 60 & 4 & 40 & 3 & 50 \\
\hline CKS & - & - & - & - & 6 & 40 & 6 & 60 & 3 & 50 \\
\hline Total & 2 & 100 & - & - & 15 & 100 & 10 & 100 & 6 & 100 \\
\hline \multicolumn{11}{|l|}{ MoCA-Ina } \\
\hline Normal (26-30) & 1 & 50 & - & - & 7 & 47 & 2 & 20 & 3 & 50 \\
\hline Ringan (20-26) & - & - & - & - & 6 & 40 & 5 & 50 & - & - \\
\hline Sedang (10-19) & 1 & 50 & - & - & 2 & 13 & 3 & 30 & 3 & 50 \\
\hline Berat (0-9) & - & - & - & - & - & - & - & - & - & - \\
\hline Total & 2 & 100 & - & - & 15 & 100 & 10 & 100 & 6 & 100 \\
\hline
\end{tabular}

Tabel 5. Distribusi gangguan fungsi kognitif menurut variabel yang diteliti

\begin{tabular}{|c|c|c|c|c|c|c|c|c|c|c|c|c|c|c|c|c|}
\hline \multicolumn{17}{|c|}{ MOCA-INA } \\
\hline \multirow[t]{2}{*}{ Variabel } & \multicolumn{2}{|c|}{$\begin{array}{c}\text { Visuospasi } \\
\text { al/Eksekuti } \\
\text { f }\end{array}$} & \multicolumn{2}{|c|}{ Penamaan } & \multicolumn{2}{|c|}{ Memori } & \multicolumn{2}{|c|}{ Atensi } & \multicolumn{2}{|c|}{ Bahasa } & \multicolumn{2}{|c|}{ Abstraksi } & \multicolumn{2}{|c|}{$\begin{array}{l}\text { Memori } \\
\text { Tertunda }\end{array}$} & \multicolumn{2}{|c|}{ Orientasi } \\
\hline & $\mathrm{n}$ & $\%$ & $\mathrm{n}$ & $\%$ & $\mathrm{n}$ & $\%$ & $\mathrm{n}$ & $\%$ & $\mathrm{n}$ & $\%$ & $\mathrm{n}$ & $\%$ & $\mathrm{n}$ & $\%$ & $\mathrm{n}$ & $\%$ \\
\hline \multicolumn{17}{|l|}{ Jenis } \\
\hline Laki-laki & 15 & 75 & 2 & 100 & 6 & 75 & 19 & 90 & 9 & 90 & 4 & 67 & 16 & 89 & 1 & 100 \\
\hline Perempuan & 5 & 25 & - & - & 2 & 25 & 2 & 10 & 1 & 10 & 2 & 33 & 2 & 11 & - & - \\
\hline Total & 20 & 100 & 2 & 100 & 8 & 100 & 21 & 100 & 10 & 100 & 6 & 100 & 18 & 100 & 1 & 100 \\
\hline \multicolumn{17}{|l|}{ Usia } \\
\hline $12-20$ thn & 6 & 30 & - & - & 5 & 63 & 13 & 62 & 4 & 40 & 2 & 34 & 9 & 50 & - & - \\
\hline 21-30 thn & 6 & 30 & 1 & 50 & - & - & 3 & 14 & 1 & 10 & 1 & 16 & 3 & 17 & - & - \\
\hline $31-40$ thn & 1 & 5 & 1 & 50 & 1 & 12 & - & - & 2 & 20 & 2 & 34 & 2 & 12 & - & - \\
\hline$>40$ thn & 7 & 35 & - & - & 2 & 25 & 5 & 24 & 3 & 30 & 1 & 16 & 4 & 21 & 1 & 100 \\
\hline Total & 20 & 100 & 2 & 100 & 8 & 100 & 21 & 100 & 10 & 100 & 6 & 100 & 18 & 100 & 1 & 100 \\
\hline \multicolumn{17}{|l|}{ Pendidikan } \\
\hline SD & 3 & 15 & - & - & 1 & 12 & 1 & 5 & 1 & 10 & 1 & 17 & 2 & 11 & - & - \\
\hline SMP & 3 & 15 & - & - & 1 & 12 & 5 & 24 & - & - & 1 & 17 & 2 & 11 & 1 & 100 \\
\hline SMA & 14 & 70 & 2 & 100 & 6 & 76 & 15 & 71 & 9 & 90 & 4 & 66 & 13 & 72 & - & - \\
\hline $\begin{array}{l}\text { Perguruan } \\
\text { Tinggi }\end{array}$ & - & - & - & - & - & - & - & - & - & - & - & - & 1 & 6 & - & - \\
\hline Total & 20 & 100 & 2 & 100 & 8 & 100 & 21 & 100 & 10 & 100 & 6 & 100 & 18 & 100 & 1 & 100 \\
\hline \multicolumn{17}{|l|}{ Berat Cedera } \\
\hline CKR & 12 & 60 & - & - & 7 & 88 & 16 & 76 & 7 & 70 & 4 & 67 & 12 & 67 & 1 & 100 \\
\hline CKS & 8 & 40 & 2 & 100 & 1 & 12 & 5 & 24 & 3 & 30 & 2 & 33 & 6 & 33 & - & - \\
\hline Total & 20 & 100 & 2 & 100 & 8 & 100 & 21 & 100 & 10 & 100 & 6 & 100 & 18 & 100 & 1 & 100 \\
\hline \multicolumn{17}{|c|}{ MOCA-INA } \\
\hline \multirow[t]{2}{*}{ Variabel } & \multicolumn{2}{|c|}{$\begin{array}{c}\text { Visuospasi } \\
\text { al/Eksekuti } \\
\text { f }\end{array}$} & \multicolumn{2}{|c|}{ Penamaan } & \multicolumn{2}{|c|}{ Memori } & \multicolumn{2}{|c|}{ Atensi } & \multicolumn{2}{|c|}{ Bahasa } & \multicolumn{2}{|c|}{ Abstraksi } & \multicolumn{2}{|c|}{$\begin{array}{l}\text { Memori } \\
\text { Tertunda }\end{array}$} & \multicolumn{2}{|c|}{ Orientasi } \\
\hline & $\mathrm{n}$ & $\%$ & $\mathrm{n}$ & $\%$ & $\mathrm{n}$ & $\%$ & $\mathrm{n}$ & $\%$ & $\mathrm{n}$ & $\%$ & $\mathrm{n}$ & $\%$ & $\mathrm{n}$ & $\%$ & $\mathrm{n}$ & $\%$ \\
\hline Skor MMSE & & & & & & & & & & & & & & & & \\
\hline Normal & 18 & 90 & 2 & 100 & 7 & 88 & 20 & 95 & 8 & 80 & 5 & 84 & 16 & 89 & 1 & 100 \\
\hline Probable & 2 & 10 & - & - & 1 & 12 & 1 & 5 & 2 & 20 & 1 & 16 & 2 & 11 & - & - \\
\hline Definite & - & - & - & - & - & - & - & - & - & - & - & - & - & - & - & - \\
\hline Total & 20 & 100 & 2 & 100 & 8 & 100 & 21 & 100 & 10 & 100 & 6 & 100 & 18 & 100 & 1 & 100 \\
\hline
\end{tabular}




\section{BAHASAN}

Penelitian ini dilakukan selama dua bulan pada pasien CKR dan CKS yang dirawat di RSUP Prof. Dr. R. D. Kandou Manado. Dari penelitian ini diperoleh 50 pasien cedera kepala yang terdiri dari 37 kasus CKR dan 13 kasus CKS.

Dalam kelompok kriteria jenis kelamin didapatkan subyek terbanyak ialah laki-laki yaitu sebesar 72\% (Tabel 1). Hasil penelitian ini serupa dengan hasil penelitian Oktaviana $^{11}$ tentang gambaran kecelakaan lalu lintas pada kendaraan bermotor roda dua di RSUPN Cipto Mangunkusumo yang mendapatkan hasil bahwa sebagian besar kecelakaan terjadi pada laki-laki yaitu 86,3\% dengan perbandingan 6,3 kali lebih besar daripada perempuan. Hal ini juga diperkuat dalam penelitian Nasution ${ }^{12}$ yang mendapatkan bahwa penderita cedera kepala akibat kecelakaan lalu lintas yang paling banyak dirawat berjenis kelamin laki-laki yaitu $73,6 \%$. Hal ini mungkin berhubungan erat dengan mobilitas dan bidang pekerjaan yang berbeda antara lakilaki dan perempuan. Laki-laki biasanya lebih sering berada dalam keadaan yang mempunyai kemungkinan terjadi kecelakaan, seperti mengendarai motor, terlibat perkelahian, pekerjaan yang berbahaya, dll, sedangkan perempuan kebanyakan memiliki pekerjaan yang lingkungan kerjanya aman dan terhindar dari risiko kecelakaan.

Dalam kelompok kriteria usia didapatkan kasus terbanyak berada dalam kelompok usia 12-20 tahun yaitu sebanyak 44\% (Tabel 1). Menurut Villaveces dan Andes (2003) tingginya angka kejadian kecelakaan pada kelompok usia aktif dan produktif dapat dikaitkan dengan tingkat mobilitas yang tinggi dan berhubungan erat dengan perkembangan kejiwaan, dimana usia remaja sampai dewasa muda perkembangan jiwanya belum stabil sehingga sering belum dapat mengendalikan emosi dirinya. Keadaan ini menyebabkan sikap yang kurang waspada, sehingga seringkali kurang memperhatikan keselamatan dirinya sendiri maupun orang lain dalam mengemudikan kendaraan. ${ }^{11}$
Dalam kelompok kriteria pendidikan yang paling banyak mengalami cedera kepala berada dalam kelompok SMA yaitu 74\%. (Tabel 1). Hal ini berhubungan dengan distribusi karakteristik menurut kelompok usia dimana kelompok usia tertinggi adalah 12-20 tahun yang memiliki tingkat mobilitas yang tinggi sehingga angka kemungkinan mengalami cedera kepala juga tinggi. Dalam penelitian Nasution ${ }^{13}$ yang bertempat di rumah sakit umum Padang Sidempuan juga menyatakan bahwa pekerjaan kasus cedera kepala akibat kecelakaan lalu lintas yang paling banyak ialah pelajar/mahasiswa (42,4\%).

Berdasarkan kriteria beratnya cedera kepala, kasus cedera kepala terbanyak berada dalam kelompok CKR yaitu 74\%. (Tabel 1). Hasil penelitian ini sama dengan data dari salah satu rumah sakit di Jakarta, RS Cipto Mangunkusumo dimana kejadian cedera kepala tertinggi ialah cedera kepala ringan. ${ }^{10}$

Hasil MMSE yang didapat (Tabel 2) menunjukkan bahwa pada kasus CKR tidak memiliki gangguan kognitif dan pada kasus CKS terdapat dua kasus yang hasil MMSE probable gangguan kognitif. Hal ini sejalan dengan penelitian Krisandi ${ }^{4}$ dimana ratarata skor MMSE penderita menunjukkan bahwa seluruh kasus tidak mengalami gangguan fungsi kognitif. MMSE mempunyai keterbatasan terhadap domain yang diperiksa dengan patofisiologi yang terjadi pada cedera kepala sehingga sering kali didapatkan hasil normal. $^{4}$

Berdasarkan hasil MoCA-Ina (Tabel 3) didapatkan lebih banyak kasus CKR dan CKS yang mengalami gangguan fungsi kognitif. Pada MMSE bagian yang paling banya mengalami kemunduran ialah atensi dan kalkulasi. (Tabel 4). Hasil MoCA-Ina yang mengalami gangguan fungsi kognitif menunjukkan adanya kemunduran pada 3-4 bagian MoCA-Ina (Tabel 5). Bagian yang paling banyak mengalami kemunduran ialah bagian atensi, visuospasial/eksekutif, dan delayed recall.

Penderita dikatakan mengalami kemunduran dalam fungsi atensi karna pada MoCA-Ina tidak dapat melakukan 
atau menyelesaikan Perhatian Rentang Angka Maju (Forward Digit Span), Rentang Angka Mundur (Backward Digit Span), kewaspadaan, dan serial 7s. Penderita yang mengalami kemunduran dalam fungsi visuospasial/ eksekutif pada MoCA-Ina karna tidak mampu menyelusuri jejak secara bergantian (Alternating Trail Making), menggambar kubus, dan menggambar jam dengan benar. Penderita yang mengalami kemundur-an dalam fungsi delayed recall dalam MoCA-Ina karena tidak mampu mengingat 5 kata yang disebutkan pada awal pemeriksaan atau sekitar 5 menit yang lalu., 14

\section{SIMPULAN DAN SARAN}

Pada penelitian yang dilakukan di RSUP Prof. Dr. R. D. Kandou Manado terhadap penderita cedera kepala ringan dan sedang didapatkan bahwa penderita cedera kepala ringan dan sedang terbanyak ialah jenis kelamin laki-laki, kelompok usia 12-20 tahun, tingkat pendidikan SMA, cedera kepala dan ringan.

Skor MMSE didapat sebagian besar normal sedangkan skor MoCA-Ina didapat peningkatan kasus cedera kepala yang mengalami penurunan skor.

Dari hasil penelitian dapat disimpulkan bahwa MoCA-Ina lebih dapat menggambarkan gangguan fungsi kognitif daripada pemeriksaan MMSE.

\section{SARAN}

Untuk penelitian selanjutnya disarankan mengenai fungsi kognitif pada pasien cedera kepala ringan dan sedang dengan total sampel yang lebih banyak, dan juga terhadap cedera kepala berat untuk mengetahui adanya gangguan fungsi kognitif.

\section{DAFTAR PUSTAKA}

1. Mallinaidu KV. Gambaran penderita trauma kapitis di unit gawat darurat Rumah Sakit Haji Adam Malik [Karya Tulis Ilmiah]. Medan: Universitas Sumatera Utara; 2010.
2. Centers of Disease Control and Prevention (CDC). Reports to congress Traumatic Brain Injury in the United States. 2015.

3. Granacher RP Jr. Traumatic Brain Injury, Methods for Clinical and Forensic Neuropsychiatric Assessment (3rd ed). London: CRC Press, 2015; p. 1-3.

4. Putri AL, Fibriani AR, Muhammad N. Hubungan trauma kepala ringan sampai sedang dengan vertigo di RSUD Dr. Moewardi Surakarta [Skripsi]. Surakarta: Universitas Mauhammadiyah; 2014.

5. Manarisip MEI, Oley $M$, Limpeleh $\mathbf{H}$. Gambaran CT Scan kepala pada penderita cedera kepala ringan di BLU RSUP Prof. Dr. R. D. Kandou Manado periode 2012-2013. eCl. 2014;2(2).

6. Ginsber L. Neurologi (8th ed). Jakarta: Erlangga, 2008; p. 117.

7. Krisandi AE, Utomo W, Indriati. Gambaran status kognitif pada pasien cedera kepala yang telah diizinkan pulang di RSUD Arifin Achmad Pekanbaru [Skripsi]. Pekan Baru: Universitas Riau; 2014.

8. Semiun Y. Kesehatan mental (3rd ed). Yogyakarta: Kanisius, 2006; p. 278.

9. Ismawati, Muis A, Akbar M, Goysal Y, Kaelan C, Satriono. Hubungan derajat klinis dan gangguan kognitif pada pasien penderita parkinson dengan menggunakan MoCA-Ina [Karya Tulis Ilmiah]. Makassar: Universitas Hasanudin; 2014.

10. Guise E, LeBlanc J, Champoux MC, Counturier C, Alturki AY, Lamoureux $\mathbf{J}$, et al. The mini-mental state examination and the montreal cognitive assessment after traumatic brain injury; an early predictive study. Brain Injury. 2013;23(12):1428-34.

11. Oktaviana F. Gambaran kecelakaan lalu lintas pada kendaraan bermotor roda dua di RSUPN Cipto Mangunkusumo tahun 2003-2007 [Karya Tulis Ilmiah]. Jakarta: Universitas Indonesia; 2008.

12. Nasution ES. Karakteristik penderita cedera kepala akibat kecelakaan lalu lintas yang rawat inap di Rumah Sakit Umum Padang Sidempuan Tahun 2005/2007 [Karya Tulis Ilmiah]. Medan: Universitas Sumatera Utara; 2010. 
13. Nasution DP. Karakteristik penderita cedera kepala akibat kecelakaan lalu lintas yang rawat inap di Rumah Sakit Umum Padang Sidempuan tahun 20002004 [Karya Tulis Ilmiah]. Medan: Universitas Sumatera Utara; 2006.
14. Panentu D, Irfan M. Uji validitas dan reliabilitas butir pemeriksaan dengan Montreal Cognitive Assessment versi Indonesia (MoCA-Ina) pada insan pasca stroke fase recovery. Jurnal Fisioterapi. 2013;13:55-67. 